\title{
O trabalho em serviços de saúde mental no contexto da reforma psiquiátrica: um desafio técnico, político e ético
}

\author{
Working in mental health services in the context of Brazilian \\ psychiatric reform: a technical, political and ethical challenge
}

\author{
José Jackson Coelho Sampaio $^{1}$ \\ José Maria Ximenes Guimarães ${ }^{1}$ \\ Cleide Carneiro ${ }^{2}$ \\ Carlos Garcia Filho ${ }^{1}$
}

${ }^{1}$ Grupo de Pesquisa Vida e Trabalho, Centro de Ciências da Saúde,

Universidade Estadual do Ceará (UECE). Av. Paranjana 1.700, Itaperi. 60740-000 Fortaleza CE. sampaiojackson@gmail.com ${ }^{2}$ Laboratório de

Humanização da Atenção e da Gestão em Saúde, Universidade Estadual do Ceará (LHUAS, UECE)

\begin{abstract}
This paper deals with mental health taken within the context of Brazilian Psychiatric Reform and profiling the transformations in the organization of work processes. This has occurred as a result of the advances with respect to the implementation of the services that replaced the classic psychiatric model and the reconfiguration of the scope of intervention and practices. From this standpoint, the paper seeks to pinpoint the contradictions and problems related to this process and its impact on the organization of work processes on the management of services and on worker health. Lastly, strategies are prepared for the purpose of tackling the problem, chief among which are the following: the redefinition of spaces, practices, and the relationships among the different actors, namely managers, workers, and users; the adoption of co-management mechanisms; and clinical-institutional supervision.
\end{abstract}

Keywords Mental health, Healthcare reform, Mental health services, Health personnel management
Resumo $O$ presente artigo aborda o trabalho em saúde mental, situando-o no contexto da Reforma Psiquiátrica, demarcando as transformações ocorridas na organização dos processos de trabalho, em decorrência dos avanços referentes à implantação dos serviços substitutivos ao modelo psiquiátrico clássico e à reconfiguração do objeto de intervenção e das práticas. Nesta perspectiva, busca-se evidenciar as contradições e problemas desse processo e seu impacto na organização dos processos de trabalhos, na gestão dos serviços e na saúde do trabalhador. Por fim, apontam-se estratégias de enfretamento da problemática evidenciada, entre as quais destacam-se: a ressignificação dos espaços, das práticas e das relações entre os diferentes sujeitos - gestores, trabalhadores e usuários; adoção de mecanismos de cogestão; e, supervisão clínico-institucional.

Palavras-chave Saúde mental, Reforma dos serviços de saúde, Serviços de saúde mental, Gestão de pessoal em saúde 


\section{Introdução}

A investigação acadêmica sobre o trabalho em saúde mental, concebido hoje na experiência brasileira como psicossocial, territorial, interdisciplinar e constituinte do campo da saúde coletiva, tem, obviamente, desenvolvimento temporal pouco maior que uma década. Consequentemente têm-se pequena magnitude, certa fragmentação e um adensamento teórico em construção na área.

Buscando apoio em elementos desenvolvidos pelas propostas psicoterapêuticas de dinâmica de grupo e pelo método dialético, percebe-se que o psicossocial é imposição da natureza do objetoproblema, o processo saúde/doença, e em recorte mais específico, o processo saúde/doença mental. A dimensão territorial é consequência da magnitude e da diversidade dos espaços de atuação, representados por populações portadoras de histórias singulares e de potências contraditórias de produção de significados, portanto de experiências e de formas vivas de expressão destas experiências. Observa-se o interdisciplinar como consequência da complexidade do conhecimento, que impede cada trabalhador de saber tudo, mas instrumentaliza as saídas dos impasses e das fragmentações por meio de um corpo coletivo de trabalho, isto é, da equipe multiprofissional, atuando sob lógica integrada.

Não há garantia de que o trabalho em equipe, para os objetivos técnicos específicos da clínica psicossocial, seja mais eficaz que o trabalho individual. Porém, tudo leva a crer em pelo menos três grandes ordens de vantagens: a) Ideológica - o trabalho em equipe impede a hegemonia de um dos vários saberes que buscam dar conta do processo saúde/doença mental, portanto a prática onipotente e acrítica; b) Teórica - o trabalho em equipe expõe as teorias à competição, obrigando-as a aperfeiçoarem seus instrumentos, a interconterem-se e a interfertilizarem-se; e, c) Organizacional - devido à complexidade crescente do conhecimento, não é mais possível, a qualquer trabalhador isolado, dar conta da totalidade de um problema, daí a equipe tornar-se imposição histórica, não escolha.

Na prática concreta do trabalho no campo das políticas públicas de atenção à saúde mental, derivadas da aplicação das propostas do Movimento Brasileiro de Reforma Psiquiátrica-MBRP, busca-se otimizar: a) Vantagens ideológicas, por meio do questionamento frequente das condutas baseadas na tradição e na rotina, pois nada mais ideológico que o senso comum, o espontâneo, o naturalizado, "o sempre foi assim", e apren- der a duvidar com competência e a respeitar saberes diversos; b) Vantagens teóricas, por meio da formulação e aplicação de novas soluções, reelaborando conceitos (reabilitação, saúde mental, doença mental, sofrimento psicológico, atividade, trabalho, linguagem), funções (ambulatório, emergência, hospital, assistência social, modos de expressão, modos de reapropriação) e dispositivos de cuidado (triagem, acolhimento, terapeuta emergente, terapia comunitária, visita domiciliar, grupo de queixa difusa); e c) Vantagens organizacionais por meio do equacionamento cuidadoso de tamanho, composição e aperfeiçoamento da equipe, estrutura de funcionamento e processo de trabalho.

O trabalho em equipe, em saúde mental, no serviço público, diante da demanda da população, exige atitudes para o enfrentamento de problemática tridimensional: entre os profissionais, oriundos de várias formações; entre a equipe e os gestores, portadores de tecnologias de gestão produzidas em outros processos de trabalho; e, entre a equipe e os usuários, estes entendidos não como consumidores ou agraciados, mas como cidadãos. Para tal, são necessárias três ordens de atitudes/valores: a) Competência - o desenvolvimento de habilidades técnicas, relacionais, comunicacionais e políticas, para a prática efetiva e qualificada da gestão e do cuidado, em campo atravessado de história e subjetividade; b) $\mathrm{Hu}$ mildade - o reconhecimento de que desvios, carências materiais, marginalidades, anormalidades, imoralidades e sofrimentos não devem ser reduzidos ao fenômeno doença, portanto não são passíveis de tratamento; c) Democracia - o reconhecimento da necessidade de desburocratizar e des-hierarquizar, desarmando enviesamentos dados pelas relações de poder para uma atuação menos competitiva, valorizando os saberes da população, compartilhando responsabilidades, inclusive assumindo a transparência na prestação de contas, no estabelecimento de critérios, nas decisões, práticas e resultados.

Pode-se otimizar a primeira atitude/valor, a competência, pela formação permanente em serviço, enfatizando o domínio das técnicas terapêuticas e o desenvolvimento das habilidades associadas ao protagonismo e à produção de grupalidade, construindo saber no serviço. Um dispositivo estratégico, por exemplo, deve ser a supervisão clínico-institucional, posto na interface entre a formação, a grupalidade e o acolhimento das demandas afetivas da equipe, por sua vez, desafiada pelas contradições interpessoais, intercorporativas, interteóricas, sobretudo pelo 
enfrentamento das tensões proporcionadas pelas demandas dos usuários.

A atitude/valor humildade deve ser expressa pelo suporte a um acordo e garantia de segurança para as decisões estabelecidas desde o primeiro contato, disparador de acolhimento às necessidades e dúvidas do demandante, mas que não assume todo sofrimento psicológico como sintoma ou pródromo de doença mental. Neste tópico, é necessário enfatizar o desenvolvimento da capacidade de dizer sim - sim ao saber das famílias, ao saber das religiões, aos saberes populares, e todos partilham da possibilidade da verdade e estruturam a identidade real da nossa população.

A democracia pode ser otimizada pela horizontalização das hierarquias e pela redução da divisão taylorista do trabalho. Entre os membros da equipe de formação superior reconhecese a existência de uma importante, porém limitada especificidade, fora dela, qualquer técnico pode ser o coordenador do projeto terapêutico de cada cliente, dependendo da natureza do nível mais imediato de determinação do caso e do estabelecimento de vínculo afetivo. Entre os membros da equipe de formação média, admite-se o rodízio de funções, o treinamento comum e a inclusão de todos, do auxiliar de enfermagem ao motorista, na categoria auxiliar de saúde mental. A prestação de contas se dá por meio do prontuário, lugar de registro de toda a equipe e, como determina o habeas data constitucional, propriedade do usuário; da participação de usuários nas reuniões da equipe; de representação da equipe nas reuniões dos conselhos integrantes dos dispositivos de controle do poder público pela sociedade; e da produção intelectual tornada pública, em eventos e em periódicos.

A ação da equipe e de cada um de seus membros subordina-se à vasta rede de determinações, hierarquizadas de modo diferente a cada momento histórico-social:

a) determinações econômicas - agem sobre a equipe e a população e resultam do modo como a sociedade promove suas condições de existência, isto é, trabalha, produz e distribui riqueza. Aqui temos a questão, por parte do serviço, da falta ou abundância de recursos, e, por parte da clientela, a natureza mais abstrata ou concreta das carências. $\mathrm{Na}$ ordem econômica capitalista geram-se as lógicas da mercadoria, onde cuidados e carinhos, competências e éticas, tornam-se valores de troca, passíveis de serem representados por dinheiro, e da alienação, onde as consequências podem até serem antagônicas às intenções que produziram os atos ${ }^{1}$; b) determinações políticas - agem sobre equipe/clientela e resultam do modo como o Estado se organiza, a favor da lógica econômica dominante ou de modo compensatório, provocando alguma redistribuição, impermeável às demandas sociais ou se deixando mover por elas, equilibrando ou não suas funções de legitimação ${ }^{2}$;

c) determinações culturais - agem sobre a equipe e a clientela e resultam do modo como o conhecimento é produzido, é distribuído e sedimenta-se na sociedade, armando representações e preconceitos, articulando a diversidade de classes e as absorções/recriações coletivas da ciência, do senso comum, da filosofia e das religiões ${ }^{3}$;

d) determinações administrativas - o modo como as determinações econômicas e políticas agem diretamente sobre a equipe, por meio da organização do processo de trabalho. A partir da consolidação de interesses econômicos e políticos, satisfeitos ou contrariados pela prática da equipe, podemos observar tanto diferenciais de recursos materiais e de prestígio disponíveis, quanto à natureza mais ou menos protegida dos regimes de contratação dos trabalhadores;

e) determinações corporativas e teóricas - o modo como as determinações econômicas e culturais agem diretamente sobre a equipe, por meio da divisão social do trabalho. As formações sociais capitalistas, após o taylorismo/fordismo, engendram competição dos diferentes grupos de função em busca da competência técnica objetiva e dos diferenciais de salário e prestígio. Os diferenciais de saber tornam-se diferenciais profissionais e logo em seguida diferenciais de poder;

f) determinações interpessoais - a formação histórica dos indivíduos, nas situações de alienação universalizada e sob a égide da mercadoria, leva à competição de todos com todos, a transformação dos indivíduos em valores de troca, ao impedimento da solidariedade e do humanismo. Sujeitos-coisa interagem instrumentalmente com sujeitos-coisa e todos buscam escapar do mundo sem coração e refugiarem-se em afetividades exacerbadas $^{4}$;

g) determinações do objeto - o sujeito que cuida e o objeto do cuidado tendem a se espelhar e a se confundir. Trata-se no outro a ameaça que o próprio sujeito vivencia de perda da identidade, de estranhamento entre significantes e significados, de angústia da dissolução e do vazio. Os rituais protetores do hospício e a desqualificação do outro como igual a mim constituem táticas bem mais simples ${ }^{5}$.

No campo da saúde mental coletiva, aplicando a lógica da atenção psicossocial territorial, 
busca-se dar conta desta multiplicidade não cartesiana de determinações que se apresentam, na maioria das vezes, de forma mascarada, umas com a face das outras, em reuniões de equipe, estudos de caso, supervisão clínico-institucional, seminários teóricos e esforço sistemático de pesquisa. No presente estudo, discute-se o trabalho em saúde mental, contextualizado no cenário de uma década do MBRP, enfatizando os problemas emergentes, com destaque para a tensa transição entre antigos e novos modelos, antigas e novas sociabilidades.

\section{Saúde Mental e Trabalho no Cenário da Política de Saúde Mental e da Gestão do Cuidado em Saúde}

O cenário histórico dos problemas a serem enfrentados é observado a partir da perspectiva do Ceará, um estado brasileiro com território de 149 mil km², no qual habitam oito milhões e meio de pessoas, que gera um Produto Interno Bruto na ordem de 60 bilhões de dólares anuais e tem por capital a cidade de Fortaleza. O território que atualmente representa o Ceará foi ocupado pelos europeus, em 1603, mais de 100 anos depois do início da colonização brasileira. O estado é produto colonial português tardio e se situa, quase totalmente, no semiárido equatorial, com população concentrada na região metropolitana da capital ${ }^{6}$.

O Ceará apresentou dinâmica própria de desenvolvimento, como a direção do processo de ocupação, do interior para o mar, contrariando o padrão brasileiro; a ausência de matérias primas coloniais; a pequena dimensão do escravismo, uma vez que a pecuária e a agricultura algodoeira baseavam-se no arrendamento de mão de obra livre; a ocupação econômica tardia, derivada da forte resistência indígena; além de irrupções de secas inclementes, de movimentos messiânicos e de pronunciamentos separatistas, até os espasmos da industrialização retardatária e truncada de hoje. Estas características determinaram e caracterizaram o quadro político e sociossanitário do estado ${ }^{6}$.

Na perspectiva da história da assistência psiquiátrica convém destacar quatro períodos significativos:

Período I - De 1603, início do processo colonial, até 1886, quando foi inaugurado o Asilo Alienados São Vicente de Paula, da Santa Casa de Misericórdia, instituição filantrópica associada à Igreja Católica. Antes de sua inauguração não houve qualquer iniciativa formal de assistência. Nestes 283 anos, o lugar do louco era a rua, a prisão e os movimentos messiânicos.

Período II - De 1887 até 1962, quando houve a inauguração do Hospital de Saúde Mental de Messejana-HSMM, instituição pública, de responsabilidade do governo estadual. Entre este hospital e o Asilo de Alienados havia ocorrido, em 1936, a instalação de um hospital privado, a Casa de Saúde São Gerardo. Em 76 anos, para dar conta, sucessivamente, das concepções de cuidado associadas à alienação, à psicopatia e à psicose, foram implantados três instituições de pequeno porte, uma filantrópica, uma privada e uma pública, e muito tardias em relação aos modelos ocidentais de origem.

Período III - De 1963 até 1991, ocasião em que se inaugura o primeiro Centro de Atenção Psicossocial-CAPS, na cidade de Iguatu, situada no sertão central. Estes 29 anos são complexos e contraditórios. A Ditadura Militar brasileira desencadeou um processo de criação de hospitais privados e o Ceará inaugurou um Manicômio Judiciário e seis hospitais psiquiátricos privados, conveniados com a Previdência Pública. Influências norte-americanas, derivadas da Mental Health Law, geraram experiências ambulatoriais e treinamento em Psiquiatria de médicos generalistas, via Programa Integrado de Saúde MentalPISAM. Paralelamente a estes dois processos, desenvolveu-se, no Ceará, uma linha autônoma do MBRP que vai resultar numa grande experiência de reforma do HSMM, na criação do CAPS de Iguatu e no início da tramitação da Lei Estadual de Reforma Psiquiátrica, a segunda do Brasil, apresentada à Assembleia Legislativa Estadual e aprovada nove anos antes da lei brasileira.

Período IV - De 1992 a 2011, são 20 anos que acompanham a implantação do Sistema Único de Saúde-SUS, iniciado em 1986, com grande pioneirismo local. O Ceará antecipa as experiências brasileiras do Programa de Agentes Comunitários de Saúde (PACS), do Programa de Saúde da Família (PSF), do Planejamento Estratégico com Programação Pactuada Integrada (PPI) e da criação das macro e microrregiões de saúde. Este período pode ser discriminado em três fases:

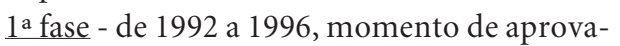
ção da Lei Estadual e criação de projetos pioneiros, bem sucedidos, que foram os CAPS de Iguatu, Canindé, Quixadá, Cascavel e Aracati, cidades situadas entre 60 e $400 \mathrm{~km}$ de distância da capital. O município de Quixadá estabeleceu um modelo de CAPS que supervisiona ações de saúde mental na atenção primária, atua como reta- 
guarda para internações em leitos psiquiátricos de hospital geral regional, promove habilitação psicossocial com apoio das políticas de inclusão social do município, oferece tratamento ambulatorial com técnicas terapêuticas diversificadas e se qualifica como modelo de atenção para municípios de médio porte.

$2^{\text {a }}$ fase - de 1997 a 2000, quando o modelo de CAPS é adotado por mais sete municípios, o governo estadual decide implantar um CAPS em cada uma das 21 microrregiões de saúde, o governo municipal de Fortaleza decide implantar um CAPS em cada Secretaria Executiva Regional da cidade ( $n=6)$ e o I Encontro Estadual de CAPS é promovido pela Universidade Estadual do Ceará (UECE). A capital, Fortaleza, não avança e desqualifica os indicadores gerais do estado, pois implantou apenas um CAPS.

3a fase - de 2001 a 2011, quando, sob impacto da morte de um cliente, na cidade de Sobral, fato que levou o Brasil a uma condenação na Corte Interamericana de Direitos Humanos, o governo municipal fecha o hospital psiquiátrico, de natureza asilar, existente na cidade, cria uma rede de serviços de saúde mental orientada pelos princípios da Reforma Psiquiátrica, ganha vários prêmios nacionais de qualidade da atenção e se organiza para oferecer modelo a cidades de médio a grande porte. Apenas neste momento a capital cearense concretamente adere à implantação de uma rede comunitária de cuidados e o governo estadual, em consequência da aprovação da Lei No 10.216, autoriza repasse de recursos federais, induz real crescimento da rede de CAPS pelas microrregiões cearenses de saúde.

Atualmente, sob gestão municipal, existem no Ceará quatro residências terapêuticas, das quais uma em Fortaleza; 116 CAPS, entre estes: cinco CAPS para a infância (CAPS i), dos quais dois em Fortaleza; 15 CAPS para álcool e outras drogas (CAPS ad), dos quais seis em Fortaleza; três CAPS III (funcionamento 24 horas), nenhum em Fortaleza; 28 CAPS II, dos quais seis em Fortaleza; e 65 CAPS I, nenhum em Fortaleza.

Para dar conta da prática de trabalho nesse novo cenário o principal recurso de intervenção é o trabalhador, amparado por sua formação, seu protagonismo, suas habilidades técnicas e relacionais. Esse reconhecimento deriva do fato de que, no campo da saúde mental, não predomina o uso denso das tecnologias de apoio diagnóstico e de tratamento presentes nas demais especialidades da saúde, baseadas em dispositivos biomédicos ${ }^{7,8}$. Reconhece-se também que os saberes e as habilidades adquiridas durante a formação profissional, embora ofereçam as principais tecnologias disponíveis, não se mostraram suficientes para os desafios. Daí a necessidade, cotidiana, de novos saberes e práticas serem construídos pelos trabalhadores, mediante a invenção e a incorporação de novas formas de lidar com a demanda.

A análise preliminar dos diferentes cenários de cuidado, no campo da saúde mental, permite defender que a assistência produzida e as condições de trabalho são realidades nas quais objetivos técnicos estão articulados aos objetivos político-institucionais, sob os quais a técnica se organiza para produzir cuidados. Esses modos de organização refletem interesses, práticas administrativas e compromissos, além da disponibilidade de meios de trabalho, de instalações e de formas de interagir com a clientela. Tudo isso conformará os padrões do desempenho profissional para o conjunto dos trabalhadores de saúde. Como consequência desses processos podem ser gerados e identificados os jogos de interesses interteóricos e intercorporativos, os conflitos, as contradições, as possibilidades de construção compartilhadas, bem como seu impacto na organização do processo de trabalho e na saúde mental do trabalhador.

\section{O Processo de Trabalho no Campo da Atenção Psicossocial Territorial}

Na rede de atenção à saúde mental, a complexidade do objeto, o sujeito que sofre e não foi desapropriado de seu contexto social, redireciona a lógica de organização dos serviços e dos processos de trabalho, os quais são impelidos à adoção crítica de uma ética e uma estética do cuidado, pautada no respeito às singularidades, na atenção integral e na reapropriação das relações com a cidade e a cidadania.

Considerando a mudança de paradigma na organização dos serviços e das práticas como conquista do MBRP, a partir do qual se desencadeou a estruturação da rede de serviços substitutivos ao modelo psiquiátrico clássico, pode-se afirmar que o palco de atuação dos trabalhadores se desloca da lógica hospitalocêntrica para uma estrutura de serviços de base territorial, cujas práticas estão direcionadas à habilitação social. Tem-se como fio condutor das ações o delineamento de linhas de cuidado fundamentadas na defesa dos direitos dos usuários, a partir do estímulo ao desenvolvimento de uma consciência cidadã, do acolhimento, do vínculo, da autonomia e da responsabilização. 
Nesse processo ocorre a aquisição de novos saberes e modos de agir em saúde, tendo em vista à adequação dos trabalhadores aos novos serviços e à rede. Ocorreu também uma inversão na lógica de organização do processo de trabalho, antes pautada pela rigidez hierárquica, pela atividade individualizada e pela separação trabalhador/produto, trabalhador/significado e objeto do trabalho. Passa-se, agora, ao desenvolvimento do trabalho em equipe, em dinâmica interdisciplinar e mais horizontal, na qual se prima pela construção coletiva dos processos de trabalho.

Visualiza-se, portanto, a incorporação de novas tecnologias, inscritas no campo relacional, as tecnologias leves ${ }^{9}$, como ferramentas imprescindíveis à operacionalidade dos processos de trabalho em saúde mental, implicando a construção de novo modo de operar as relações dos trabalhadores entre si e destes com os gestores e usuários dos serviços. Assim, percebe-se que, como qualquer trabalho vivo em ato, o processo de trabalho em saúde mental, em todas as fases de sua realização, está sempre sujeito aos desígnios do trabalhador em seu espaço autônomo, particular, de concretização da prática. Desta forma não é passível de total controle como nos modos de produção fabril/taylorista.

A oposição ao modelo manicomial e ao psiquiátrico clássico imprimiu significativas modificações nas relações de poder entre usuários e trabalhadores. Enquanto nos asilos e nos hospitais psiquiátricos tradicionais a relação é marcada pela hierarquia rígida, pela cisão entre sujeito e objeto do conhecimento, pelo uso da violência institucionalizada e pelo controle nos serviços substitutivos, as relações devem ser construídas a partir de lógica diversa. Aqui, o trabalhador passa a ser um facilitador nas negociações dos projetos dos usuários, mediando propostas tanto do lado destes como do lado da sociedade ${ }^{10}$.

No âmbito das instituições psiquiátricas clássicas, apesar da atuação de diversas categorias profissionais compondo equipes multiprofissionais, a organização do trabalho fundamentava-se no modelo médico-hegemônico. Os trabalhadores atuavam de modo subordinado ao saber e à prescrição médica, inexistindo equilíbrio entre os saberes cuja articulação é demandada pela complexidade do objeto, transformados em reféns do saber e do poder da Psiquiatria.

$\mathrm{Na}$ construção da atenção psicossocial ocorrem modificações nos modos de organizar os processos de trabalho e de produzir suas ações. Tal situação impôs a urgência de ampliação das equipes de saúde mental numa perspectiva de atender as necessidades de saúde apresentadas pelos usuários, buscando integrar o homem em suas diversas dimensões: biológica, existencial, cultural, socioeconômica, ético-política, filosófica e religiosa. Segundo as normas do Ministério da Saúde ${ }^{11}$, os CAPS devem ter uma equipe mínima, cujos critérios de inclusão das categorias profissionais são: a população adstrita, a complexidade e o projeto terapêutico do serviço. Emerge, portanto, a dimensão de trabalho em equipe fundamentada na interdisciplinaridade, rompendo a fragmentação dos saberes e a hierarquização das relações.

No âmbito da clínica na atenção psicossocial, observa-se a construção de uma clínica do coletivo, sem prejuízo das ações de caráter individual. Em resposta aos desafios de respeitar a singularidade dos sujeitos e de atender as suas necessidades, as equipes têm implantado uma lógica de organização do trabalho a partir do acolhimento, da construção de projetos terapêuticos singulares com a definição de técnicos de referência e discussão coletiva de casos clínicos de maior complexidade ${ }^{12}$. Destaca-se a inserção dos usuários em grupos terapêuticos e ocupacionais, em conformidade com suas necessidades e desejos, inclusive com a perspectiva de inserção no mercado de trabalho.

No âmbito da gestão, tem-se buscado alternativas frente ao desafio de desenvolver linhas de cuidado, mediante a construção e a consolidação de redes de atenção à saúde mental, com sistema de referência e contrarreferência. Alguns dispositivos têm possibilitado esse processo, entre eles o matriciamento em saúde mental na atenção primária e o acompanhamento e o monitoramento das internações hospitalares pelas equipes dos CAPS.

Diante dos avanços, desafios, conflitos e contradições desses processos, apresentam-se à gestão do trabalho demandas que necessitam serem equacionadas, particularmente aquelas percebidas pelo coletivo de trabalhadores.

\section{Contradições e problemas que emergem no cotidiano dos trabalhadores na atenção psicossocial}

Os desdobramentos da Reforma Psiquiátrica, presentes no caso do município de Fortaleza, particularmente no referente à implantação dos CAPS, oferecem um ângulo privilegiado para refletirmos acerca dos avanços e dos efeitos adversos desse processo nas equipes de trabalhadores, no contexto de implantação, organização e gestão dos dispositivos. 
Em estudos anteriores, desenvolvidos por autores do presente $\operatorname{artigo}^{7,13-15}$, foi constatado que apesar do investimento ideológico, político e técnico dos trabalhadores na construção dos serviços substitutivos, da priorização desses equipamentos na agenda política, diversos problemas têm emergido no cotidiano das suas equipes. A própria implantação dessa rede de serviços não constituiu prioridade nos orçamentos públicos, com reflexos na estrutura das instituições e nas condições de trabalho da equipe.

Os trabalhadores têm referido que as condições de trabalho são insatisfatórias, do ponto de vista das instalações físicas, com espaços pequenos e/ou inadequados para o desenvolvimento das atividades, da escassez de materiais e equipamentos, da carência de profissionais ocasionando a formação de equipes pequenas e a sobrecarga de trabalho, dos baixos salários e dos vínculos empregatícios precarizados, com insuficiência de formação continuada em serviço ${ }^{13,14}$.

Durante o processo contínuo de supervisão de dois CAPS Gerais, em Fortaleza, por um ano foram identificados problemas relacionados à organização da demanda em articulação com a rede geral de atenção à saúde, à organização do acolhimento a clientela, à agenda de ofertas de cuidados de saúde em acordo com a disponibilidade do serviço, à definição de fluxos de cuidados à saúde e de indicadores de desempenho, à avaliação permanente dos projetos terapêuticos dos clientes segundo o plano terapêutico do serviço, com definição e comprometimento de um técnico de referência.

No funcionamento dos CAPS, os trabalhadores sinalizaram a existência de dissonâncias entre as diretrizes da política de saúde mental e a operacionalidade dos serviços. Nesse plano, considera-se que diversos problemas têm limitado a resolutividade dos serviços: a ausência de uma rede de saúde mental estruturada e devidamente articulada com as demais redes assistenciais, cujo desdobramento é a dificuldade de contenção de crises e consequente não redução significativa das reinternações psiquiátricas; conflitos entre as dimensões da autonomia do sujeito e a tutela pelo serviço e o assistencialismo das políticas de Assistência Social; conflito entre o modelo de formação e a atuação na atenção psicossocial; dificuldade na gestão do território; a dificuldade teórica e prática na gestão dos projetos terapêuticos individuais e coletivos; e terapêutica dominantemente centrada na erradicação de sintomas mediante a prescrição massificada de drogas.

A sinergia destes elementos conduz, na tensa situação da transição de modelos, a uma percep- ção individual e coletiva, por parte dos trabalhadores, de prazer e sofrimento, o que configura uma dinâmica muito particular de saúde mental destes atores.

Nesta perspectiva, identifica-se que esses modos de estruturação e gestão dos serviços, de organização dos processos de trabalho, impactam na satisfação da equipe de saúde mental. Essa problemática tem o potencial de ocasionar insatisfação no trabalho e sofrimento psíquico no coletivo de trabalhadores. Aliás, a insatisfação constitui uma expressão de sofrimento. Nesse sentido, Ferreira e Mendes ${ }^{16}$ defendem que o prazer-sofrimento é uma vivência subjetiva do próprio trabalhador, mas que pode ser compartilhada coletivamente e influenciada pelo trabalho. Pensar o sofrimento como vivência, a qual pode ser compartilhada, significa inseri-lo na dimensão política, uma vez que envolve a presença do outro no campo da existência do sujeito.

No caso dos CAPS de Fortaleza, o sofrimento psíquico tem se manifestado como: decepção com o serviço e com o trabalho desenvolvido; angústia; sentimentos de culpa por não alcançar os resultados esperados, mesmo que não dependa somente de sua atuação. Evidencia-se, ainda, danos à saúde física, expressos nas queixas de estresse e dores decorrentes do trabalho ${ }^{13,14}$.

Entretanto, a dinâmica prazer-sofrimento no trabalho em saúde mental não constitui uma especificidade dos CAPS de Fortaleza. Achados semelhantes foram encontrados em estudo realizado no Rio de Janeiro ${ }^{17}$, onde emergiram problemas como a sobrecarga de trabalho, a tensão existente na transição dos modelos assistenciais, a precarização/valorização do trabalho, refletindo no sofrimento dos trabalhadores.

A responsabilização do trabalhador com o cuidado e a especificidade do lidar com o processo saúde-doença mental também tem impactado na dinâmica prazer-sofrimento no trabalho. De um lado, os aspectos relacionais estabelecidos entre os diferentes atores nos CAPS, os resultados positivos alcançados junto aos usuários, a possibilidade de inovar e construir projetos capazes de implementar e de consolidar o modelo de atenção psicossocial são fontes de prazer. Por outro lado, a sobrecarga de trabalho, as particularidades da função de terapeuta de referência e os casos clínicos de difícil manejo podem se constituir fonte de sofrimento ${ }^{14,17,18}$.

Essa complexa problemática, seu impacto na satisfação do trabalhador e sua relação com a dinâmica prazer-sofrimento no trabalho, impõe à gestão o desafio de adotar estratégias de enfretamento objetivando a solução ou minoração 
desses problemas, com vistas à melhoria da qualidade de vida no trabalho, o que em última instância, impacta na qualidade dos serviços prestados.

\section{Considerações Finais}

A atuação da equipe de saúde mental nos serviços substitutivos tem sido marcada por avanços na construção do modelo de atenção psicossocial, porém marcada pela emergência de contradições e ampla problemática intrínseca ao processo de implantação desses equipamentos, com repercussão na configuração dos processos de trabalho, nas relações estabelecidas entre os diferentes atores, na satisfação e na dinâmica prazer/ sofrimento dos trabalhadores.

Os discursos dos trabalhadores de saúde mental, contendo queixas referentes aos baixos salários, aos entraves burocráticos para a realização de projetos inovadores, às precárias condições de trabalho, à falta de espaços para reflexão das práticas, muitas vezes não revelados nos documentos oficiais dos gestores, expressam a falta de investimentos financeiros, com vista à consolidação e à qualificação da atenção.

Considerando a dimensão da responsabilidade/comprometimento dos trabalhadores, particularmente dos terapeutas de referência, com o cuidado prestado aos usuários, chama-se atenção para o fato de que o profissional não deve assumir a responsabilidade pela totalidade existencial, sucessos, insucessos e modos de andar a vida do usuário no território, sob o risco de sobrecarga e de sofrimento pelos possíveis fracassos, inerentes à condição humana, que este venha a ter em sua vivência na cidade.

A tarefa deve ser compartilhada com a equipe, e mais que isso, respeitar a autonomia do usuário de modo que ele seja corresponsável pelo projeto terapêutico. Isto implica em consciência dos limites, tanto da capacidade de intervenção de cada trabalhador, quanto da dimensão econômicooperacional do processo de reforma psiquiátrica.

Por outro lado, enseja desenvolvimento de habilidades. É preciso que as equipes busquem aprofundar e aperfeiçoar procedimentos que permitam o ordenamento da demanda, a qualificação do processo de trabalho e, apesar das limitações estruturais, primar pela resolutividade dos serviços. Definir, de forma clara, como deve ser a articulação com a rede de atenção, o relacionamento com a Justiça e com as políticas de assistência, tanto quanto com as de emprego e renda.

Torna-se evidente a necessidade de adoção de estratégias de enfrentamento dessa problemáti- ca. Conforme proposto por Rollo ${ }^{19}$, essas estratégias podem ser desenvolvidas em três âmbitos: 1. individual do trabalhador - acompanhamento individual em programas de atenção biopsicossocial, com equipe interdisciplinar. Enfim, estruturação da atenção à saúde do trabalhador na instituição; 2. coletivo da equipe - estabelecer as metas e os objetivos da equipe de forma participativa, com processo avaliativo regular, mais autonomia para a reorganização do processo de trabalho, entre outras estratégias; e, 3. instituição/rede/organização - descentralização e democratização do poder, mediante o empoderamento dos trabalhadores, reconhecimento e celebração de resultados, criação de programas e processos de educação permanente.

Esforços nessa perspectiva vêm sendo adotados no Brasil, por meio da implantação da Política Nacional de Humanização da Gestão e da Atenção em Saúde-PNH, cujas diretrizes apontam para o cuidado sensível aos usuários dos serviços de saúde, ressignificação dos espaços de atuação dos trabalhadores e das relações no âmbito organizacional ${ }^{19}$.

Procura-se, portanto, a valorização do trabalho, mediante a ressignificação das estruturas, dos processos e das relações, com transformações das formas de sociabilidade que envolvam trabalhadores, gestores e usuários em sua experiência cotidiana de produção, organização e condução dos serviços de saúde, enfim mudanças nos modelos de gestão. ${ }^{7}$

Para tal, aposta-se na democratização e na horizontalização da relações de comando, expressas na possibilidade de participação dos diferentes atores nos processos decisórios, potencializada pela implementação de instâncias colegiadas e rodas de equipe; no estímulo e respeito à autonomia dos sujeitos e coletivos no contexto institucional, o que possibilita ampliar seu potencial de compreensão e de intervenção no mundo do trabalho e, ao mesmo tempo, permitindo a corresponsabilização e o aumento da satisfação no trabalho ${ }^{7}$.

A supervisão clínico-institucional apresentase como dispositivo potente para qualificar o cuidado na atenção psicossocial, a organização dos processos de trabalhos e a promoção da reflexão sobre os processos de gestão. Ela tem o potencial de promover a reflexão crítica entre os trabalhadores e minimizar o risco de reprodução das práticas psiquiátricas clássicas.

Enfim, constitui tarefa especial da supervisão clínico-institucional, por exemplo, devolver para a equipe, discriminando as várias determinações que estejam atuando numa crise ou numa supe- 
ração de crise, seja do usuário, do grupo social adstrito ou da própria equipe. Vive-se uma obra aberta, em progresso, sensível a mudar a cada alteração do perfil sócio-econômico-político-demográfico-cultural da cidade, da oferta de cuidados e da demanda dos usuários.

\section{Colaboradores}

JJC Sampaio, JMX Guimarães, C Carneiro e C Garcia Filho participaram igualmente de todas as etapas de elaboração do artigo.

\section{Referências}

1. Bottomore T. Dicionário do pensamento marxista. Rio de Janeiro: Jorge Zahar; 2001.

2. Gramsci A. Maquiavel, a política e o Estado Moderno. $5^{\text {a }}$ ed. Rio de Janeiro: Civilização Brasileira; 1984.

3. Bourdieu P. A produção da crença: contribuição para uma economia dos bens simbólicos. Porto Alegre: Editora Zouk; 2001.

4. Lasch C. Refúgio num mundo sem coração.1 a ed. São Paulo: Paz e Terra; 1991.

5. Schaff A. La alienación como fenómeno sociale. Barcelona: Editorial Crítica; 1979.

6. Anuário do Ceará 2009-2010. Jornal O POVO (Fortaleza) 2009.

7. Sampaio JJC, Guimarães JMX, Abreu LM. Supervisão Clínico-institucional e a Organização da Atenção Psicossocial no Ceará. São Paulo: Hucitec; 2010.

8. Rebouças D, Abelha L, Legay LF, Lovisi GM. O trabalho em saúde mental: um estudo de satisfação e impacto. Cad Saude Publica 2008; 24(3):624-632.

9. Mehry EE. Saúde: a cartografia do trabalho vivo. $3^{\text {a }}$ ed. São Paulo: Hucitec; 2007.

10. Koda MY. A construção de sentidos sobre o trabalho em um Núcleo de Atenção Psicossocial. In: Amarante P, organizador. Arquivos de Saúde Mental e Atenção Psicossocial. Rio de Janeiro: NAU editora; 2003. p. 89-120.

11. Brasil. Ministério da Saúde(MS). Legislação em saúde mental 1990-2004. 5a ed. ampliada. Brasília: Ministério da Saúde (MS); 2004.

12. Brasil. Ministério da Saúde(MS). HumanizaSUS política nacional de Humanização: documento base para gestores e trabalhadores do SUS. $1^{\text {a }}$ ed. Brasília: Ministério da Saúde(MS); 2004.

13. Guimarães JMX, Jorge MSB, Assis MMA. (In)satisfação com o trabalho em saúde mental: um estudo em Centros de Atenção Psicossocial. Cien Saude Colet 2011; 16(4):2145-2154.

14. Guimarães JMX. Satisfação dos trabalhadores de saúde mental: o caso dos Centros de Atenção Psicossocial de Fortaleza-Ceará [dissertação]. Fortaleza (CE): Universidade Estadual do Ceará; 2007.

15. Garcia-filho C. O abuso de cocaina e crack na atenção psicossocial: a relação entre o significado atribuído e as praticas terapêuticas dos trabalhadores [monografia]. Fortaleza(CE): Universidade Estadual do Ceará; 2009. 
16. Ferreira MC, Mendes AM. "Só de pensar em vir trabalhar, já fico de mau humor": atividade de atendimento ao público e prazer-sofrimento no trabalho. Estud Psicol (Natal) 2001; 6(1):93-104.

17. Vasconcelos VC, Azevedo CS. Sentidos do trabalho e imaginário organizacional em um Centro de Atenção Psicossocial - CAPS. Interface - Comun Saúde Educ 2010; 14(34):563-576.

18. Silva EA, Costa II. O profissional de referência em Saúde Mental: das responsabilizações ao sofrimento psíquico. Rev. Latinoam. Psicopat. Fund 2010; 13(4):635-647.

19. Rollo AA. É possível valorizar o trabalho em saúde num mundo "globalizado"?. In: Santos-Filho SB, Barros MEB, organizador. Trabalhador da saúde: muito prazer! Protagonismo dos trabalhadores na gestão do trabalho em saúde. Ijuí: Ed. Unijuí; 2007. p. 19-61.

Apresentado em 08/09/2011

Aprovado em 30/09/2011

Versão final apresentada em 05/10/2011 